\title{
Sublingual Tablets : An Overview
}

Rohit S. Nikam*, Smita P Borkar, Dr. Prakash D Jadhav, Vishal D. Yadav, Apurva V Jadhav

Arvind Gavali College of pharmacy. Jaitapur, Dist - Statra,Maharashra, India

Corresponding Author E-mail : rohitnikam225@gmail.com

\begin{abstract}
Drug delivery via the oral mucous membrane is considered to be a promising alternative to the oral route. Subli ngual route is a useful when rapid onset of action is desired with better patient compliance than oraly ingested $t$ ablets. In terms of permeability, the sublingual area of the oral cavity (i.e. the floor of the mou) is more permea ble than the buccal (cheek) area, which in turn is more permeable than the palatal (roof of the mouth) area. A rapid onset of pharmacological effect is often desired for some drugs, especially those used in the treatment of acute disorders. Sublingual tablets disintegrate rapidly and the small amount of saliva present is usually sufficient for achieving disintegration of the dosage form coupled with better dissolution and increased bioavailability.
\end{abstract}

Keywords : Bioavailability, Sublingual tablets, Sublingual route, Drug delivery, Solid medicament.

\section{INTRODUCTION}

Sublingual drug delivery (SL) of the medication implies arrangement of the medication under the tongue and drug comes to straightforwardly into the circulation system through the ventral surface of the tongue and floor of the mouth. The fundamental system for the retention of the medication into oral mucosa is by means of latent dissemination into the lipoidal film. The retention of the medication through the sublingual course is 3 to 10 times more prominent than oral course and is just surpassed by hypodermic infusion. For these details, the little volume of spit is generally adequate to bring about tablet crumbling in the oral cavity. ${ }^{[1-5]}$

Solid medicaments may be administered orally as powders, pills, cachets, capsules or tablets. These dosage forms contain a quantity of drug which is given as a single unit and they are known collectively as solid unit dosage forms, even in the case of sustained action preparations which, technically, contain the equivalent of several normal doses of drug. ${ }^{[6]}$

Systemic drug delivery through the sublingual route had emerged from the desire to provide immediate onset of pharmacological effect. Sublingual route usually produces a faster onset of action than orally ingested tablets and the portion absorbed through the sublingual blood vessels bypasses the hepatic first pass metabolic processes. ${ }^{[7]}$ Because of underdeveloped muscular and nervous system swallowing problems is common in children's, and this could be easily overcome with the help of fast disintegrating sublingual tablets. Oral route of drug administration has been considered as the most popular one because it holds an edge over other routes such as it is the most natural, uncomplicated, convenient, safe means to administer drugs, greater flexibility in dosage form design, ease of production and low cost. By selecting the appropriate pharmaceutical excipients in the correct proportion, in combination with optimal 
manufacturing techniques the sublingual tablets could be prepared effectively. ${ }^{[8]}$

\section{SUBLINGUAL TABLETS}

They are to be placed under the tongue and produce immediate systemic effect by enabling the drug absorbed directly through mucosal lining of the mouth beneath the tongue. The drug absorbed from stomach goes to mesenteric circulation which connects to stomach via portal vein. Thus absorption through oral cavity avoids first pass metabolism. The tablets are usually small and flat, compressed lightly to keep them soft. The tablet must dissolve quickly allowing the drugs to be absorbed quickly. The depicts the drugs which have been used in formulation of sublingual tablets. ${ }^{[9]}$ It is designed to dissolve in small quantity of saliva. After the tablet is placed in the mouth below the tongue, the patient should avoid eating, drinking, smoking and possibly talking in order to keep the tablet in place. Swallowing of saliva should also be avoided since the saliva may contain dissolved drug. Bland excipients are used to avoid salivary stimulation. The excipients used in formulation of sublingual tablets. Various techniques can be used to formulate rapidly disintegrating or dissolving tablets. ${ }^{[10]}$ Direct compression is one of these techniques which require incorporation of a superdisintegrant into the formulation, or the use of highly water-soluble excipients to achieve fast tablet disintegration. Direct compression does not require the use of water or heat during the formulation procedure and is the ideal method for moisture and heat-labile medications.[11]

\section{Advantages ${ }^{[12,13]}$}

1. Ease of administration to patients who refuse to swallow a tablet, such as pediatric, geriatric patients and psychiatric patients.
2. Convenience in administration of drug and accurate dosing as compared to liquid formulations.

3. Water is not required for swallowing the dosage form, which is convenient feature for patients who are traveling and do not have immediate access to water.

4. Good mouth feels property helps to change the basic view of medication as "bitter pill", particularly for pediatric patients.

5. Fast dissolution of medicament and absorption which will leads to rapid, onset of action.

6. Some drugs are absorbed from the mouth pharynx and oesophagus as the saliva passes down into the stomach, in such cases bioavailability of drugs is increased.

7. It provides advantages of liquid formulations in the form of solid dosage form.

8. Pregastric absorption can result in improved bioavailability and as a result of reduced dosage, improved clinical performance through a reduction of unwanted effects.

\section{Disadvantages $^{[14,15]}$}

1. Since sublingual administration of drugs interferes with eating, drinking, and talking, this route is generally considered unsuitable for prolonged administration.

2. Although this site is not well suited to sustained-delivery systems.

3. Sublingual medication cannot be used when a patient is uncooperative or unconscious.

4. The patient should not smoke while taking sublingual medication, because smoking causes vasoconstriction of the blood vessels. This will decrease the absorption of the medication.

\section{MECHANISM INVOLVED IN SUBLINGUAL ABSORPTION}

The absorption potential of buccal mucosa is affected by the lipid solubility and therefore the permeability 
of the solution (osmosis), the ionization $(\mathrm{pH})$, and the molecular weight of the substances. ${ }^{[16,17]}$ In sublingual glands, the pattern of different branches are compact.8The venous blood from the sublingual region of the oral cavity drains into a common trunk, which then drains through the internal jugular vein, the subclavian vein, and the brachiocephalic vein directly into the superior vena cavaun like in oral administration. ${ }^{[18]}$

\section{DRUGS FOR SUBLINGUAL ADMINISTRATION}

Sublingual drug administration is applied in the field of cardiovascular drugs, steroids, some barbiturates and enzymes. It has been a developing field in the administration of many vitamins and minerals which are found to be readily and thoroughly absorbed by this method. Sublingually absorbed nutrition, which avoids exposure to the gastric system and liver, means direct nutritional benefits, particularly important for sufferers of gastro-intestinal difficulties such as ulcers, hyperactive gut, coeliac disease, those with compromised digestion, the elderly and invalids the nutritional benefit is independent of gastro-intestinal influences. ${ }^{[19,20]}$ Examples of drugs administered by this route include antianginal like nitrites and nitrates, anti hypertensive like nifedipine, analgesics like morphine and bronchodilators like fenoterol. Certain steroids like estradiol and peptides like oxytocin can also be administered e.g. fentanyl citrate, apomorphine, prochlorperazinedimaleate (PRO), and hydrazine $\mathrm{HCl}$ (HYD).

\section{FACTORS AFFECTING THE SUBLINGUAL ABSORPTION ${ }^{[21]}$}

\section{Solubility in Salivary Secretion}

In addition to high lipid solubility, the drug should be soluble in aqueous buccal fluids i.e. biphasic solubility of drug is necessary for absorption.

\section{Binding to Oral Mucosa}

Systemic availability of drugs that bind to oral mucosa is poor.

\section{3.pH and pKa of The Saliva}

As the mean $\mathrm{pH}$ of the saliva is 6.0, this $\mathrm{pH}$ favors the absorption of drugs which remain unionized. Also, the absorption of the drugs through the oral mucosa occurs if the pKa is greater than 2 for an acid and less than 10 for a base.

\section{Lipophilicity of Drug}

For a drug to be absorbed completely through sublingual route, the drug must have slightly higher lipid solubility than that required for GI absorption is necessary for passive permeation.

\section{Thickness of Oral Epithelium}

As the thickness of sublingual epithelium is $100-200$ $\mu \mathrm{m}$ which is less as compared to buccal thickness. So the absorption of drugs is faster due to thinner epithelium and also the immersion of drug in smaller volume of saliva.

\section{Methods of Preparation}

Following methods can be used to prepare sublingual tablets

1. Direct compression Method

2. Compression molding

3. Freeze-drying

\section{Direct compression method}

This is a commonly used method for preparation of sublingual dosage forms and it is a simple and most economical method. Direct compression Method is best suitable for heat labile drugs. In this method we are using direct compressible and soluble ingredients, lubricant and a superdisintegrant (for example Crospovidone, Micro crystalline cellulose etc.), dry binder, sweeteners and flavors ${ }^{[22-24] .}$ 


\section{Compression molding}

Tablets produced by this method will disintegrate and dissolved rapidly (within 4 to $11 \mathrm{sec}$ ). Disadvantage of this method is tablets having poor mechanical strength, to overcome this problem binders are added to formulation blend.

\section{Freeze-drying}

This is costly and consumes more time compared to directcompression; this method produces tablets of poor mechanical strength. Tablets produced by this method will have high porosity and dissolve instantly. This method is suitable for heat sensitive drugs.

\section{In vitro evaluation:}

\section{a) General appearance ${ }^{[25,26]}$}

The general appearance of a tablet like its visual identity and over all "elegance" is necessary for consumer acceptance\& compliance. General appearance characters include are tablet's size, colour, shape, presence or absence of an odour, surface texture, taste, physical flaws and legibility of any identifying marking.

\section{b) Uniformity of weight ${ }^{[27]}$}

According to I.P. procedure, weight of twenty tablets has to be determined individually and collectively on a digital weighing balance. The average weight of one tablet was calculated.

\section{c) Hardness and thickness [28]}

Ten tablets were taken and their thickness was determine by using micrometer. Hardness of tablet is defined as the force applied across the diameter of the tablet in the order to break the tablet. Hardness of the sublingual tablet was determined using Monsanto Hardness tester.

\section{d) Friability ${ }^{[29,30]}$}

Friability is the measurement of mechanical strength of tablets. For the determination of the friability
Roche friabilator is used. A preweighed tablet was placed in the friability apparatus. This apparatus consist of a plastic- chamber that revolves at $25 \mathrm{rpm}$ and dropping those tablets at a height of 6 inches in each revolution. The tablets were rotated in the friability apparatus for at least four minutes. At the end of tested tablets were dusted and reweighed again and percentage friability was calculated.

\%Friability= Initial Weight -Final Weight/ Initial Weight $\mathrm{x} 100$

\section{e) Disintegration time (DT) ${ }^{[31]}$}

A relatively easy method with rigorous conditions has been successfully developed to evaluate the DT of sublingual tablets. Each individual tablet is dropped into $10-\mathrm{mL}$ glass test tube $(1.5-\mathrm{cm}$ diameter containing $2 \mathrm{ml}$ distilled water, and the time need for complete tablet disintegration is observed visually and recorded using as stopwatch. The visual inspection can be enhanced by gently rotating the test tube at a 45 degree, without agitation.

\section{f) Wetting time (WT) ${ }^{[32,33]}$}

It is useful quality control tool for sublingual tablets. Using this test, the time required to penetrate the moisture in tablet completely is measured that correlated with the time required to release the drug in the presence of saliva.

\section{g) Water absorption ratio ${ }^{[33]}$}

A section of tissue paper folded twice is placed in a small Petri dish Containing $6 \mathrm{ml}$ of water. One tablet is placed on the tissue paper and allowed to completely wet by water. The wetted tablet is then weighted. Water absorption ratio can be represented by $\mathrm{R}$ was determined using following equation.

$$
\mathrm{R}=100 \times \mathrm{Wa}-\mathrm{Wb} / \mathrm{Wa}
$$

Where, $\mathrm{Wa}=$ Weight of tablet following water absorption

$\mathrm{Wb}=$ Weight of tablet before water absorption 


\section{h) Drug Content ${ }^{[34-39]}$}

Arbitrary ten tablets are selected from formulation, finely powdered and powder equivalent to certain $\mathrm{mg}$ of drug is weighed accurately. Different dilutions are made and drug content is precisely calculated

i) In-vitro dissolution studies ${ }^{[35-38]}$ Dissolution study was carried out in paddle type apparatus using $300 \mathrm{~mL}$ of stimulated salivary fluid $(\mathrm{pH}$ 6.8) as dissolution medium at 50 revolution per minutes. Temperature of the dissolution medium was maintained at $37 \pm 0.5^{\circ} \mathrm{C}$. Samples were diluted accordingly and estimated spectrophotometrically. The dissolution studies were conducted in triplicate.

\section{CONCLUSION}

Drug delivery through the sublingual route had emerged from the desire to provide immediate onset of pharmacological effect. Dysphasia (difficulty in swallowing) is a common problem of all age groups, especially geriatrics, pediatric, and patients who are mentally retarded, uncooperative, nauseated or on reduced liquid intake/diets have difficulties in swallowing these dosage forms. So, other absorptive mucosa is considered as potential sites for drug administration. Trans-mucosal routes of drug delivery (i.e. the mucosal linings of the nasal, rectal, vaginal, ocular, and oral cavity) offer several advantages over peroral administration for systemic delivery. This review highlights the sublingualdosage forms of advantages, Disadvantages, various evaluation parameters and commercially available sublingual dosage forms.

\section{VII.ACKNOWLEDGEMENT}

Authors are highly Acknowledge the help of teaching staff of ArvindGavali College of Pharmacy.Jaitapur, Satara. For providing necessary information required for review work. Also,we are highly Acknowledge the help and guidance of Mrs. Smita P Borkar, Dr.Prakash D Jadhav, Mr.Vishal D. Yadav, Miss. Apurva V. Jadhav.

\section{REFERENCES}

[1]. Pistiki A, Galani I, Pyleris E, Barbatzas C, Pimentel M, et al. (2014) In vitro activity of rifaximin against isolates from patients with small intestinal bacterial overgrowth. Int J Antimicrob Agents 43: 236-241.

[2]. Mantry PS, Munsaf S (2010) Rifaximin for the treatment of hepatic encephalopathy. Transplant Proc 42: 4543-4547.

[3]. Rivkin A, Gim S (2011) Rifaximin: New Therapeutic Indication and Future Directions. ClinTher 33: 812-827.

[4]. Zhang X, Duan J, Li K, Zhou L, Zhai S (2007) Sensitive quantification of rifaximin in human plasma by liquid chromatography-tandem mass spectrometry. J Chromatogr B 850: 348-355.

[5]. Valentin T, Leitner E, Rohn A, Zollner-Schwetz I, Hoenigl M, et al. (2011) Rifaximin intake leads to emergence of rifampin-resistant staphylococci. J Infect 62: 34-38.

[6]. Birudaraj R, Berner B, Shen S, Li X. Buccal permeation of Buspirone: Mechanistic studies on transport pathways. J Pharm Sci2005 ; 94: 70-78.

[7]. Price TM, Blauer KL, Hansen M, Stanczyk F, Lobo R, Bates GW. Single dose pharmacokinetics of sublingual versus oral administration of micronized 17 beta estradiol. Obstet Gynecol. 1997; 89:340-345.

[8]. Kurosaki Y, Takatori T, Nishimura H, Nakayama T, Kimura T. Regional variation in oral mucosal drug absorption permeability and degree of keratinization in hamster oral cavity. Pharm Res 1991;8:1297-1301.

[9]. Allen LV. Rapid dissolving technology : an interview with loyd. Allen. International 
journal of pharmaceutical technology 2003;7:449-450.

[10]. Fu Y, Yang S, Jeong SH, Kimura S, Park K. Orally fast disintegrating tablets: developments, technologies, taste masking and clinical studies. Crit Rev Ther Drug Carrier system 2004;21:433476.

[11]. Richman MD, Fox D, Shangraw RF. Preparation and stability of glyceryl trinitrate sublingual tablets prepared by direct compression. Journal of pharmaceutical science 1965;54(3):447-451.

[12]. Al-Ghananeem AM, Malkawi AH, Crooks PA. Effect of ph on sublingual absorption of oxycodone hydrochloride. AAPS Pharm Sci Tech 2006; 7(1): Article 23.

[13]. Rubinstein NH. 2000 Tablets In; Aulton\%o, M.E(Ed), Pharmaceutics, the Science of Dosage Form Design Churchill Livingstone, Edinburgh London on Melbourne and New York, Page 305.

[14]. Bhati R, Nagrajan RK. A detailed review non oral mucosal drug delivery system. IJPSR 2012; Vol3 (1):659- 681.

[15]. Reddy LH. IJPS 2002;0975-1491

[16]. Narang N, sharma J. Sublingual mucosa as a route for systemic drug delivery. Int J Pharm PharmSci 2011;3(2): 18-22

[17]. Denny PC, Ball WD, Redman RS. Salivary glands: a paradigm fordiversity of gland development. Crit Rev Oral Biot Med1997; 8(1): 51-75.

[18]. Bind AK, Gnanarajan G and kothiyal P.A review: sublingual route for systemic drug delivery. Int. J. Drug res. Tech2013; 3 (2):31-36.

[19]. Katz, M and Barr, M (1955), "A study of sublingual absorption I. Several factors influencing the rate of adsorption", J Am Pharm AssocAm Pharm Assoc, 44(7), 419-423.

[20]. Allen, LV (2003), "Rapid-dissolve technology: an interview", Int J Pharm Technol, 7,449-450.
[21]. Fu, Y; Yang, S; Jeong, SH;Kimura, S and Park, $\mathrm{K}(2004)$, "Orally fast disintegrating tablets: developments, technologies, taste making and clinical studies", Crit Rev Ther Drug Carrier Syst, 21,433-476.

[22]. The European Agency for the Evaluation of Medicinal Products EMA (2001) Committee for Proprietary Medicinal Products (CPMP) Note for guidance on the investigation of Bioavailability and Bioequivalence, London.

[23]. Perry R (2010) Perspectives on the bioequivalence and therapeutic equivalence of generic formulations: An overview of the landscape. ClinTher 32: 1796- 1797.

[24]. WHO (2006) Technical Report series, Fortieth Report, Geneva.

[25]. Patel P et al. Sublingual route for the systemic delivery of ondansetron. Int. J. Drug Dev\& Res 2011; 3 (4): 36- 44.

[26]. Prajapati B, Kaur S, RoopiniSA.Formulation and evaluation of mouth dissolving sublingual tablets of cimetidine to treat abdominal cramps. International Journal of Pharmaceutical Science Invention2014; 3 (9):41-46.

[27]. Godbole $\mathrm{AM}$ et al.Formulation and in-vitro evaluation of sublingual tablets of ondansetron hydrochloride using coprocessed excipients, Indian Journal of Pharmaceutical Education and Research 2014;48: 7-17.

[28]. SheuMT et al. Rapid-onset sildenafil sublingual drug delivery systems: in vitro evaluation and in vivo pharmacokinetic studies in rabbits. Journal of Pharmaceutical Sciences 2016; 105: 27742781.

[29]. Rao GK et al. Formulation and evaluation of sublingual tablets of oxazepam. International Journal of Universal Pharmacy and Bio Sciences 2013; 2(6):35-46.

[30]. Satyam ZC, Parmeshwar K and Pallavi D. Formulation and evaluation of mucoadhesive sublingual tablet of rosuvastatin calcium. 
Journal of Chemical And Pharmaceutical Research 2014; 6(8):375-383.

[31]. Madhagi Wet al. Formulation and Evaluation of New Glimepiride Sublingual Tablets. Journal of Pharmaceutics 2017; 1-5.

[32]. Yadav S, Garg S, Pareek AK, Kumar P and Kumar M. Formulation and optimization of sublingual tablet of ramipril.Journal Of Chemical And Pharmaceutical Research 2015; 7(8): 1077-1086.

[33]. Akbar M, Panda N, Reddy AV.Formulation and evaluation of doxofylline sublingual tablets using sodium starch glycolate and crosscarmellose sodium as superdisintegrant. Int. j. pharm. res. allied sci 2015; 4(2):90-100.

[34]. Grover I, Aggarwal G. Formulation and evaluation of lisinopril. J SciInd Res 2012; 71:413-417.

[35]. Bhupinder B, SaritaJ.Formulation and evaluation of fast dissolving sublingual films of rizatriptan benzoate. Int. j. drug dev. res. 2012; 4(1): 133-143.

[36]. Aparna B, Kumar B, Gnanaprakash K, Gobinath M, Y Ramesh. Development and evaluation of sublingual tablets of aripiprazole. International Journal of Biopharmaceutics2014; 5(4): 251-257.

[37]. Sheeba FR, Giles D, Rameshwari S, AnandhiJ.Formulation and evaluation of nifedipine sublingual tablets. Asian J Pharm Clin Res 2009; 2(3): 44-48.

[38]. Raju KN, Velmurugan S, Deepika B, Vinushitha S. Formulation and invitroevaluation of buccal tablets of metoprolol tartrate. Int J Pharm PharmSci 2011;3(2): 239-246.

[39]. Bredenberg $S$ et al. In vitro and in vivo evaluation of a new sublingual tablet system for rapid oromucosal absorption using fentanyl citrate as the active substance. Eur J Pharm Sci 2003; 20:327-334

\section{Cite this article as :}

Rohit S. Nikam, Smita P Borkar, Dr. Prakash D Jadhav, Vishal D. Yadav, Apurva V Jadhav, "Sublingual Tablets : An Overview", International Journal of Scientific Research in Science and Technology (IJSRST), Online ISSN : 2395-602X, Print ISSN : 23956011, Volume 7 Issue 3, pp. 333-339, May-June 2020. Available

doi : https://doi.org/10.32628/IJSRST207357

Journal URL : http://ijsrst.com/IJSRST207357

(n)

